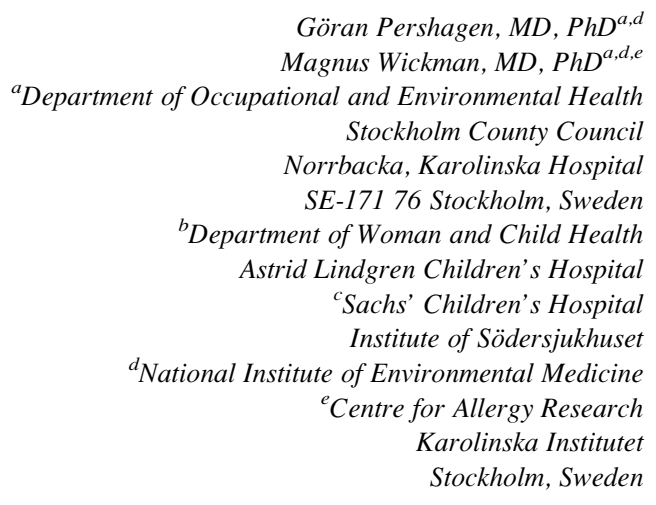

REFERENCES

1. Hoekstra M, Niers L, Steenhuis J, Roovers M, Knol E, Uiterwaal C. Is randomization of breast-feeding feasible? J Allergy Clin Immunol 2005; 115:1324.

2. Kull I, Almqvist C, Lilja G, Pershagen G, Wickman M. Breast-feeding reduces the risk of asthma during the first 4 years of life. J Allergy Clin Immunol 2004;114:155-70.

3. Kramer MS. Does breast feeding help protect against atopic disease? biology, methodology and a golden jubilee of controversy. J Pediatr 1988; 112:81-90.

4. Gartner LM, Morton J, Lawrence RA, Naylor AJ, O'Hare D, Schanler RJ, et al. American Academy of Pediatrics Section on Breastfeeding: breastfeeding and the use of human milk. Pediatrics 2005;115:496-506.

Available online April 25, 2005 doi:10.1016/j.jaci.2005.03.013

\section{On the hygiene hypothesis: Regulation down, up, or sideways?}

\section{To the Editor:}

We would like to comment on the recent review by Douwes et al, ${ }^{1}$ which addresses some interesting issues dealing with interpretation of recent epidemiological findings related to the hygiene hypothesis. They emphasize the importance of downregulation of the adaptive immune response after environmental exposure to LPS (lipopolysaccharides) and other pathogen-associated molecular patterns (PAMPs). However, we find that a few additional aspects should be mentioned that may contribute to a more focused and fruitful discussion.

Both a shift in $\mathrm{T}_{\mathrm{H}} 1 \rightarrow \mathrm{T}_{\mathrm{H}} 2$ response and an increased immunological regulatory activity are able to regulate the immune activity. An abundance of epidemiological evidence indicates that a shift in the $\mathrm{T}_{\mathrm{H}} 1 \rightarrow \mathrm{T}_{\mathrm{H}} 2$ phenotype in populations domestically exposed to animals is possible (see the review by Douwes et $\mathrm{al}^{1}$ ). This has led to the assumption that the responsible parameter might be LPS. German studies of school children have shown that the ex vitro reactivity to LPS is attenuated with increasing domestic exposure to LPS, and at the same time, the immune system is activated via upregulation of cellular receptors. This should increase the reactivity after LPS and other PAMPs exposure. However, the reaction to LPS is probably counteracted by subsequent activation of the
BPI/PLUNC (bactericidal/permeability-increasing protein/palate, lung, and nasal epithelial clone) superfamily, leading to scavenging of LPS, rendering persons relatively more susceptible to the other PAMPs.

The Toll-like receptor 4 (TLR4) receptor is a major player in LPS activation. So far, TLR4 polymorphisms have been linked only to bronchial hyporesponsiveness in the farming population. Moreover, the available studies on the role of CD14 polymorphisms have been equivocal. Furthermore, recent studies have shown that only the farm children with wild-type TLR2 were protected from allergy. $^{2}$ TLR1-2 and TLR2-6 heterodimers recognize $\beta$-glucans, peptidoglycan, and lipoproteins, indicating that the effect may be mediated by PAMPs other than LPS.

The epidemiological evidence for a downregulation of atopic activity is extremely scarce. Douwes et $\mathrm{al}^{1}$ point out that one small prospective Austrian study involving 11 skin prick test-positive farm children followed for 3 years suggests that downregulation might play a role. However, this study has some methodological limitations apart from its size, including selection bias and lack of exposure data. Other studies supporting this hypothesis are all crosssectional studies among occupational groups with exposure to organic dust.

We believe that future studies of the beneficial effects of exposure to organic dust should include other PAMPs and markers of PAMPs, particularly peptidoglycan, because this component is associated with LPS-exposure, and the susceptibility is upregulated through TLR2 increase in LPS-exposed people. This is the only way to disentangle the influence of regulatory $\mathrm{T}$ cells and different LPS inhibitors orchestrating the beneficial effects of organic dust exposure on human beings. One intriguing new piece of evidence pointing toward a new putative mechanism is the fact that IL-10 upregulation is associated with induced IgG4 production instead of IgE during antibody stimulation. ${ }^{3}$ With these data taken together, it will be very interesting to study the concomitant exposure to PAMPs and aeroallergens in prospective cohorts of persons environmentally and occupationally exposed to high amounts of PAMPs.

$$
\begin{array}{r}
\text { Torben Sigsgaard, } M D, P h D^{a} \\
\text { Dick Heederik, } P h D^{b} \\
{ }^{b} \text { Institute of Public Health } \\
\text { Department of Environmental and Occupational Medicine } \\
\text { University of Aarhus } \\
\text { Vennelyst Boulevard } 6 \\
\text { DK-8000 Aarhus C } \\
\text { Denmark } \\
{ }^{b} \text { Division of Environmental and Occupational Health } \\
\text { Institute for Risk Assessment Sciences } \\
\text { Utrecht University } \\
\text { The Netherlands }
\end{array}
$$

\section{REFERENCES}

1. Douwes J, Le Gros G, Gibson P, Pearce N. Can bacterial endotoxin exposure reverse atopy and atopic disease? J Allergy Clin Immunol 2004; 114:1051-4. 
2. Eder W, Klimecki W, Yu L, Von Mutius E, Riedler J, Braun-Fahrlander C, et al. Toll-like receptor 2 as a major gene for asthma in children of European farmers. J Allergy Clin Immunol 2004;113:482-8.

3. Nouri-Aria KT, Wachholz PA, Francis JN, Jacobson MR, Walker SM, Wilcock LK, et al. Grass pollen immunotherapy induces mucosal and peripheral IL-10 responses and blocking IgG activity. J Immunol 2004; 172:3252-9.

Available online March 23, 2005. doi:10.1016/j.jaci.2005.01.060

\section{Reply}

To the Editor:

We thank Sigsgaard and Heederik ${ }^{1}$ for highlighting two issues regarding our Rostrum ${ }^{2}$ : (1) the relevance of other pathogen associated molecular patterns (PAMPs), and (2) the potential for alternative immunological mechanisms underlying the presumed protective effects of PAMPs.

The main hypothesis of our Rostrum is that certain environmental exposures can modify the immune response from an atopic to a nonatopic state at any time in life. ${ }^{2}$ Although we have focused on LPS (lipopolysaccharides) (since most of the evidence points toward LPS), we agree that other PAMPs may be equally (or more) important. As discussed in our Rostrum, there is evidence that exposure to peptidoglycans, $\mathrm{CpG}$ containing DNA, and certain viruses may also reduce the risk of atopic disease. Other agents such as mycobacterial lipoglycans (particularly lipoarabinomannan and phosphatidylinositol mannan $)^{3}$ and even fungal components as suggested in a recent European multicenter study in farmers' children (presented at the 2004 European Respiratory Society Congress) may play a role as well. However, the evidence for these PAMPs is scarce.

In their correspondence, the authors suggest that a protective effect is more likely mediated by other PAMPs on the basis of the potential role of Toll-like receptor (TLR)-2 and their suggestion that "TLR4 polymorphisms have been linked to bronchial hyporesponsiveness only in the farming population." We disagree, because several studies in children (both farming and nonfarming) have shown that genetic variations in TLR4 are also associated with specific $\operatorname{IgE}$ and atopic asthma (including one study referenced by the authors). ${ }^{4}$ This, in our view, supports the hypothesis that endotoxin plays at least a partial role. Results regarding TLR4, atopy, and asthma have been mixed, however, hampering a straightforward interpretation.

As noted by Sigsgaard and Heederik, ${ }^{1}$ the epidemiological evidence for a downregulation of atopic activity is limited. However, there is additional evidence that LPS and other PAMPs may reverse pre-existing allergy in animals (see our Rostrum ${ }^{2}$ ). The converse has also been demonstrated, showing that a loss of protective exposures at some stage in life may result in an upregulation of atopic activity (or a loss of tolerance). For example, a recent longitudinal study in 402 adults in Denmark showed an approximately 3-fold increased risk for new-onset atopy in subjects who migrated from a low-risk rural area to a high- risk urban area. ${ }^{5}$ Other studies involving subjects migrating from poor to more affluent countries showed a similar effect. This adds to the evidence that atopy appears to be a continuum rather than a fixed immunological state, which can be both upregulated and downregulated at any time of life depending on the level of immunoregulatory exposures (including PAMPs). Taken together with the mainly indirect evidence of the occupational studies (see Rostrum), we believe there is sufficient evidence to warrant future studies to test this hypothesis.

In summary, including other markers of PAMPs (in addition to LPS) in future studies as suggested by Sigsgaard and Heederik ${ }^{1}$ is highly relevant. Similarly, a further characterization of the immunological mechanisms is essential in identifying the therapeutic potential of these PAMPs.

$$
\begin{array}{r}
\text { Jeroen Douwes, PhD }{ }^{a} \\
\text { Graham LeGros, } P h D^{b} \\
\text { Peter Gibson, } P h D^{c} \\
\text { Neil Pearce, PhD, DSc }{ }^{a} \\
{ }^{a} \text { Centre for Public Health Research } \\
\text { Massey University } \\
\text { Wellington Campus } \\
\text { Private Box } 756 \\
\text { Wellington, New Zealand } \\
{ }^{b} \text { Malaghan Institute of Medical Research } \\
\text { Victoria University } \\
\text { Wellington, New Zealand } \\
{ }^{c} \text { Airway Research Centre } \\
\text { John Hunter Hospital } \\
\text { Newcastle, Australia }
\end{array}
$$

Dr Douwes is supported by a Sir Charles Hercus Research Fellowship from the Health Research Council of New Zealand. The Centre for Public Health Research is supported by a Program Grant from the Health Research Council of New Zealand.

\section{REFERENCES}

1. Sigsgaard T, Heederik D. On the hygiene hypothesis: regulation down, up or sideways? J Allergy Clin Immunol 2005;115:1325-6.

2. Douwes J, Le Gros G, Gibson P, Pearce N. Can bacterial endotoxin exposure reverse atopy and atopic disease? J Allergy Clin Immunol 2004; 114:1051-4

3. Sayers I, Severn W, Scanga CB, Hudson J, Le Gros G, Harper JL. Suppression of allergic airway disease using mycobacterial lipoglycans. J Allergy Clin Immunol 2004;114:302-9.

4. Fageras Bottcher M, Hmani-Aifa M, Lindstrom A, Jenmalm MC, Mai $\mathrm{XM}$, Nilsson L, et al. A TLR4 polymorphism is associated with asthma and reduced lipopolysaccharide-induced interleukin-12(p70) responses in Swedish children. J Allergy Clin Immunol 2004;114:561-7.

5. Linneberg A. Hypothesis: urbanization and the allergy epidemic-a reverse case of immunotherapy. Allergy 2005;60:538-9.

Available online April 5, 2005. doi:10.1016/j.jaci.2005.01.061

\section{Safety of penicillin administration to patients with histories of penicillin allergy}

To the Editor:

In the letter by Daulat et al $^{1}$ entitled "Safety of cephalosporin administration to patients with histories of penicillin allergy," the authors minimize the cross-reaction 